\title{
Oral-Facial-Digital Syndrome Type II (Mohr Syndrome) in Palestine
}

\author{
Allam Fayez Abuhamda ${ }^{*}$ and Aymen Elsous ${ }^{2}$ \\ ${ }^{1}$ Gaza Strip's Neonatal Intensive Care Units, Ministry of Health, Gaza Strip, Palestine \\ ${ }^{2}$ Assistant professor, Faculty of Health Profession, Israa University, Gaza Strip, Palestine
}

*Corresponding author: Allam Fayez Abuhamda, Senior Consultant Neonatologist, Gaza Strip's Neonatal Intensive Care Units, Ministry of Health, Gaza strip, Palestine, Tel: +00972597502720; E-mail: allam570@yahoo.com

Received Date: October 15, 2018; Accepted Date: October 22, 2018; Published Date: October 26, 2018

Citation: Abuhamda AF, Elsous A (2018) Oral-Facial-Digital Syndrome Type II (Mohr Syndrome) in Palestine. Ann Clin Lab Res Vol.6 No.4: 259.

\section{Abstract}

Oral-facial-digital syndrome (OFDS) is a group of disorders characterized by oral cavity malformation, facial deformities and digits anomalies. There are at least 13 forms of OFDS, in which most of them have brain anomalies and different degrees of mental retardation. We have reported two cases with quite different dysmorphic features.

The first case was a female and had wide-spaced eyes, wide nose bridge, middle line cleft of upper lip, cleft soft palate, microglossia, micrognathia, polydactyly and syndactyly of the upper and lower limbs. Moreover, she had congenital hypotonia. Brain and abdominal ultrasound studies were normal. The baby's mother had a history of losing her first pregnancy resulted from intrauterine fetal death who was presented with similar dysmorphic features.

The second case was a 4-year-old male who had dysmorphic features; Antimongoloid eye slant, prominent ears, broad nose bridge, high arched palate, cleft soft palate, lingual nodule, preaxial and postaxial polydactyly with syndactyly in both hands, bilateral bifid thumbs and bilateral clinodactyly. Feet had polydactyly with syndactyly, and bifid big toe shape. The first time, that two cases with characteristic features of oral facial digital syndrome type II to be diagnosed in two Palestinian siblings of different family with consanguineous marriage.

Keywords: Oral-facial-digital syndrome; Polydactyly; Syndactyly; Cleft upper lip; Cleft soft palate

\section{Introduction}

Oral-Facial-Digital Syndrome (OFDS) is a congenital disorder characterized with a variety of clinical abnormalities including: hypotelorism, hypertelorism, wide nose bridge, cleft lip, cleft palate, microglossia, micrognathia, retrognathia, preaxial polydactyly, postaxial polydactyly, clinodactyly, polycystic kidney disease and diverse forms of CNS defects resulting in different degrees of mental retardation, delay of speech and motor control deficit. There is at least 13 types of OFDS and each form is classified according to the existing anomalies. OFDS could be autosomal dominant, autosomal recessive, $X$ linked dominant or X-linked recessive [1,2]. The OFD1 (OralFacial-Digital Syndrome Type I) gene provides instructions for making a protein whose function is not fully understood. It appears to play an important role in the early development of many parts of the body, including the brain, face, limbs, and kidneys. Mutations in the OFD1 gene prevent cells from making enough functional OFD1 protein, which disrupts the normal development of these structures $[3,4]$. Diagnosis of OFD syndrome type I when suspected, may be confirmed by genetic testing [5]. We present two cases of OFDS type II, which is a rare autosomal recessive disorder [6] giving that the gene responsible is still unknown and the incidence is 1 per 3 lakhs live births $[7,8]$.

\section{Case Reports}

\section{Case 1}

The parents were cousins and mother was G3P1. The first pregnancy ended at 30 weeks of gestational age as a result of intrauterine fetal death. The fetus was female and presented with dysmorphic features. She had polydactyly, syndactyly, cleft palate and cleft lip. Same thing happened to the second pregnancy and typically at same gestational age, however, the female baby showed normal physical examination.

The first sibling was a full term, a female baby born through normal vaginal delivery and her birth weight was $2800 \mathrm{mg}$. Her Apgar score was 7 and 9 at 1 and 5 minutes respectively. Findings from physical examination after birth were: small eyes, broad nose bridge, midline cleft upper lip, microglossia, cleft palate and micrognethia. Both hands have clinodactyly and preaxial polydactyly as there are 7 fingers (duplicate thumb). There is also syndactyly between thumbs (bifid thumb) in each hand. Both feet have Talipes equinovarus and preaxial polydactyly as there are 7 toes (duplicate big toe). Furthermore, a syndactyly between two big toes (Bifid big toes) (Figures 1-6). She had normal external female genitalia. She was hypotonic but able to move all limbs symmetrically. The respiratory system function and hemodynamic status were stable (Figure 7). Brain ultrasound, abdominal ultrasound, and echocardiography were all normal. One day after birth, we 
started feeding by orogastric tube, and she tolerated the feedings and passed stool normally (Figure 8). She was discharged home at the age of 3 days in a good general condition and referral was written for consultations of maxillofacial, hands, orthopaedic and plastic surgery.

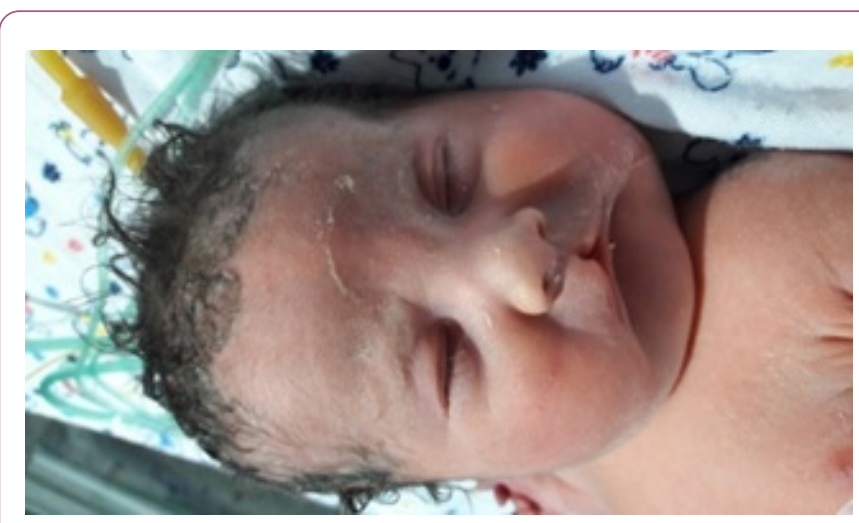

Figure 1 Small eye, broad nose bridge, medline cleft upper lip and micrognathia.

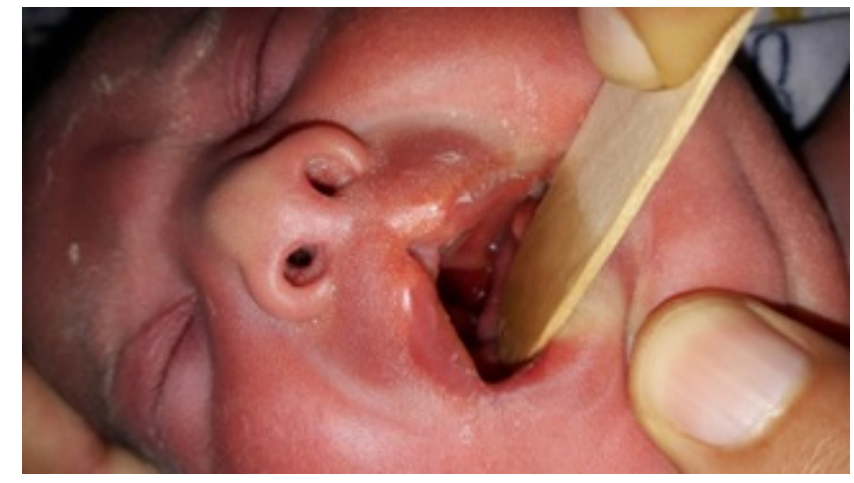

Figure 2 Cleft palate.

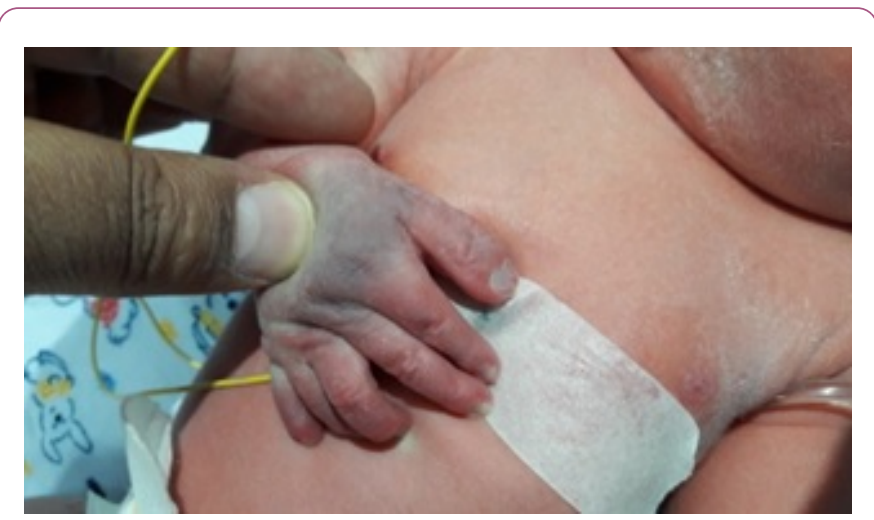

Figure 3 Right hand; polydactyly and syndactyly (bifid thumb).

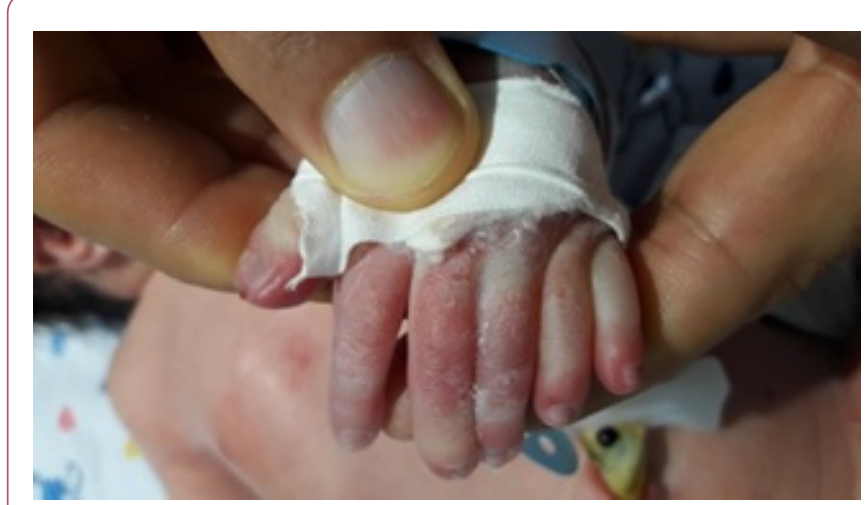

Figure 4 Left hand; polydactyly and syndactyly (bifid thumb).

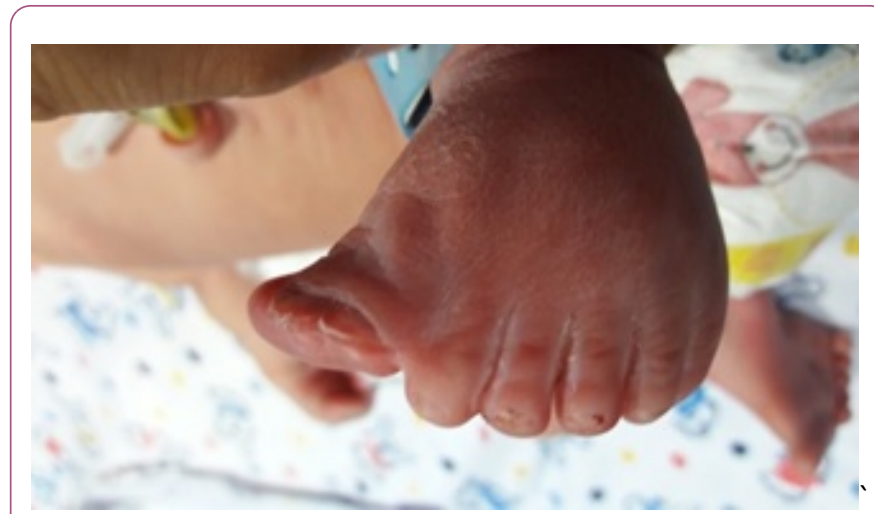

Figure 5 Left foot; polydactyly, syndactyly (bifid toe) and Talipes equinovarus.

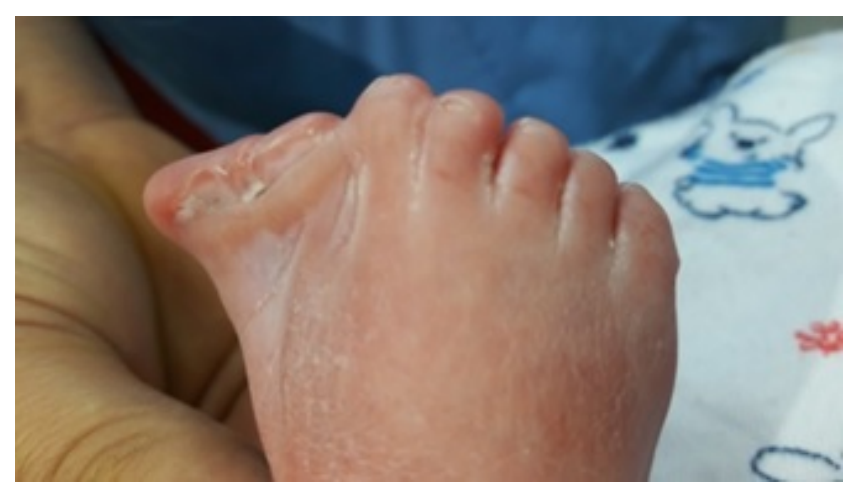

Figure 6 Right foot; polydactyly, syndactyly (bifid toe) and Talipes equinovarus. 


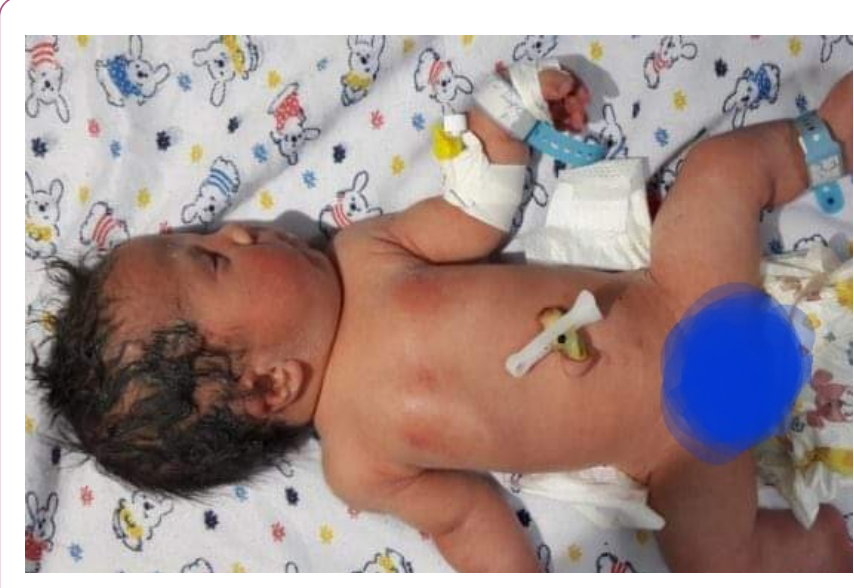

Figure 7 Congenital hypotonia.

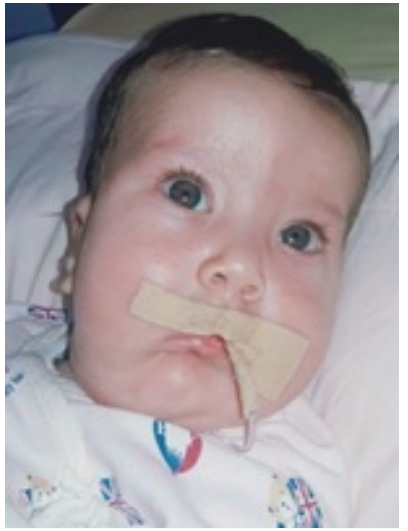

Figure 8 Orogastric tube feedings at the age of 7 months.

\section{Case 2}

Parents were cousins and had no previous family history of congenital anomalies. The male baby was their first sibling and the first time was seen at the age of 4 years. By physical examination, the child had some abnormal features; Antimongoloid eye slant, prominent ears, broad nose bridge (Figure 9), high arched palate, cleft soft palate, lingual nodule (Figure 10), preaxial and postaxial polydactyly with syndactyly in both hands, bilateral bifid thumbs and bilateral clinodactyly (Figure 11). Both foot had polydactyly with syndactyly, and bifid big toe shape (Figures 12 and 13). The child had a clear micropenis and undescended testes (Figure 14). Karyotyping study result showed normal study $(46, x y)$. Brain CT, echocardiography and abdominal renal ultrasonography were also normal. The baby suffered from a global developmental delay. Similar dysmorphic features appeared to the second sibling male baby, however he passed away at age of 2 months.

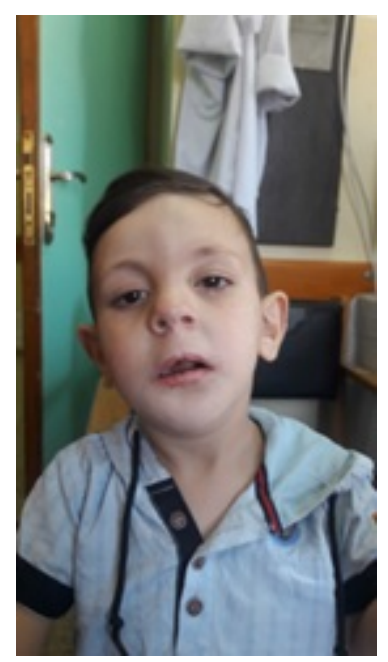

Figure 9 Anti-mongoloid eye slant, prominent ears, and broad nose.

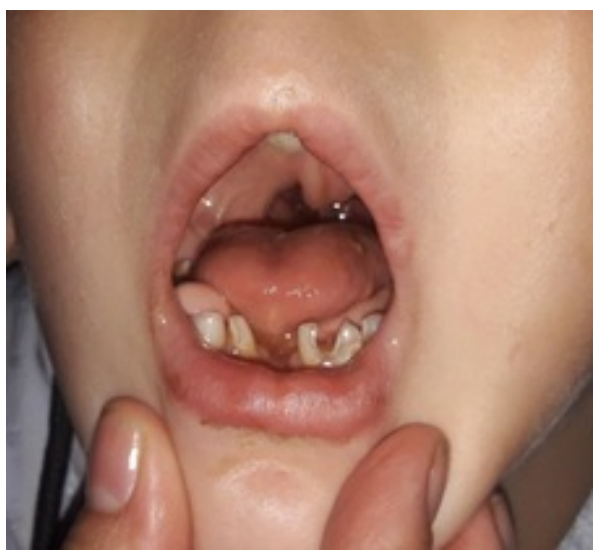

Figure 10 High arched palates, cleft soft palate and lingual nodule.

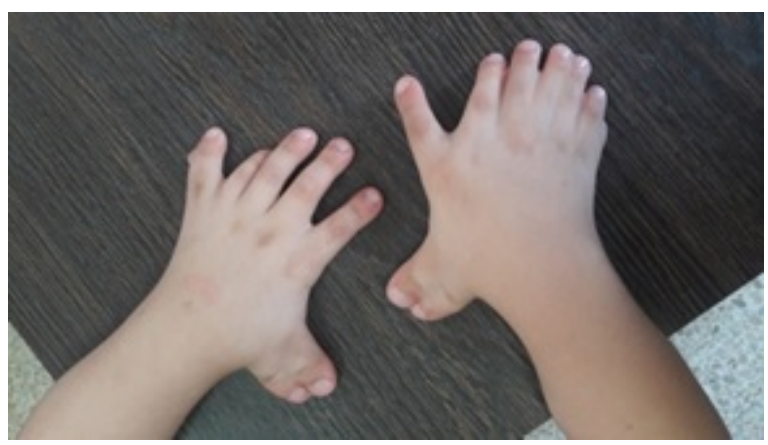

Figure 11 Preaxial, postaxial polydactyly with syndactyly in both hands and bilateral hand bifid thumbs shape. 


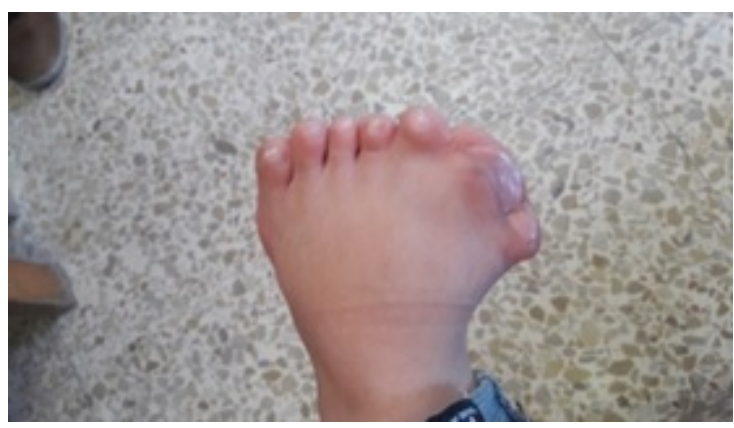

Figure 12 Left feet; feet had preaxial, posaxial polydactyly with syndactyly and bifid big toe shape.

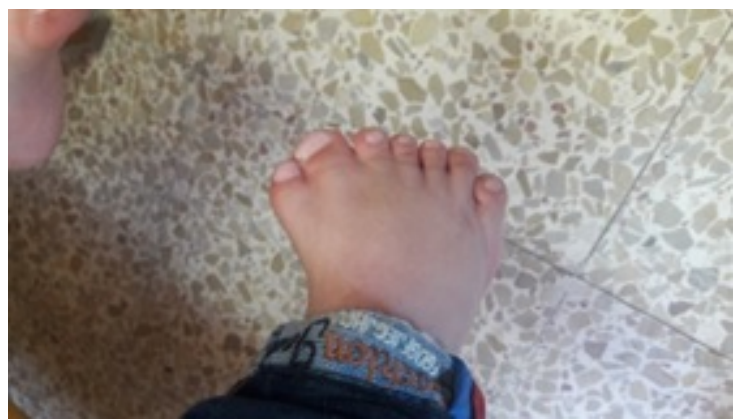

Figure 13 Right foot; feet had preaxial, posaxial polydactyly with syndactyly and bifid big toe shape.

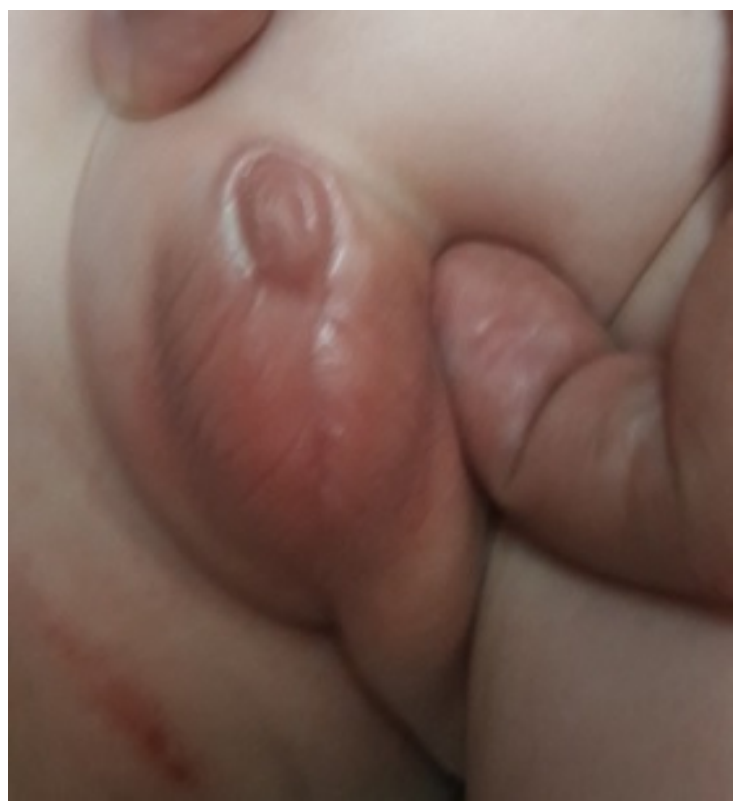

Figure 14 Micropenis and undescended testes.

\section{Discussion}

In both cases, the parents were consanguineous [9] and had characteristic features of oral facial digital syndrome type II which include; broad nose bridge, high arched palate, cleft palate, lingual nodule, hands had preaxial, postaxial polydactyly with syndactyly in both hands, and bifid thumb shape. Also feet preaxial, postaxial polydactyly with syndactyly and bifid big toe shape. Oral-facial-digital syndrome (OFDS) type II (Mohr Syndrome) can be diagnosed from the medical history and physical examination of the patient [10-12]. Both cases required consultation and follow up with plastic surgery, maxillofacial surgery, hand surgery for reconstruction and repair of the anomalies. Moreover, follow up with audiology and dentist was applied. The $2^{\text {nd }}$ case also needed follow up with pediatric surgery regarding undescended testes. Both cases need; multidisciplinary team approach to follow up different complaints, to coordinate between different medical specialties, and to observe the global development [13].

\section{Conclusions and Recommendations}

- Two rare cases were presented with clinical signs of oral facial digital syndrome type II in Palestinian children.

- Consanguineous marriage in Palestinian people carries a high risk for congenital anomalies. Therefore, it is recommended to avoid relative marriage as possible.

\section{Ethical Approval}

Hospital permission was obtained to review infant's medical file and collect the necessary information. Parental/guardian consent obtained to set for interview and provide additional information not found in infant's medical file, and to show baby's whole face.

\section{Availability of Data}

Data is available and under request with first author

\section{Conflict of Interest}

The authors declare no conflict of interests.

\section{References}

1. Fiorella G, Franco B, Toriello H, Neri G (2007) Oral-facial-digital syndromes: A review and diagnostic guidelines. Am J Med Genet 143 (24): 3314-3323.

2. Anneren $\mathrm{G}$, Gustavson $\mathrm{KH}$, Jozwiak S, Kjartansson S, Strömberg B (1990) Abnormalities of the cerebellum in oro-facio-digital syndrome II (Mohr syndrome). Clin Genet 38(1): 69-73.

3. Brunella F, Thauvin-Robinet C (2016) Update on oral-facialdigital syndromes (OFDS). Cilia 5(1): 12.

4. Lopes CA, Prosser SL, Romio L, Hirst RA, O'Callaghan C, et al. (2011) Centriolar satellites are assembly points for proteins implicated in human ciliopathies, including oral-facial-digital syndrome 1. J Cell Sci 124(4): 600-612.

5. Toriello HV, Franco B, Bruel AL, Thauvin-Robinet C (2016) Oralfacial-digital syndrome type I. Gene Reviews [Internet].

6. http://www.omim.org/entry/252100. 
7. Alessandro SC, Dallapiccola B (2005) Oro-facial-digital Syndrome, Type II. Abnormal skeletal phenotypes: From simple signs to complex diagnoses pp: 787-790.

8. Biswas A, Ghosh JK, Sinha MK, Basu K, Chatterjee S (2009) MohrClaussen syndrome or oro-facial-digital syndrome (OFDS) type-II. J Pak Med Assoc 59(7): 484-486.

9. Ahmad ST (2010) Genetic disorders among Arab populations. Springer Science \& Business Media.

10. http://www.orpha.net/consor/cgi-bin/OC_Exp.php? Ing=en\&Expert $=2751$.
11. Ajacques JC (1981) Mohr's syndrome: Type II orofaciodigital syndrome (author's transl). Revue de stomatologie et de chirurgie maxillo-faciale 82(4): 234-240.

12. Sakai N, Nakakita N, Yamazaki Y, Ui K, Uchinuma E (2002) Oralfacial-digital syndrome type II (Mohr syndrome): Clinical and genetic manifestations. J Craniofac Surg 13(2): 321-326.

13. Ouwens $M$, Wollersheim $H$, Hermens $R$, Hulscher $M$, Grol $R$ (2005) Integrated care programmes for chronically ill patients: A review of systematic reviews. Int J Qual Health Care 17(2): 141-146. 